\title{
HUBUNGAN HIPERTENSI DENGAN FUNGSI KOGNITIF MENGGUNAKAN MINI MENTAL STATE EXAMINATION (MMSE) PADA PASIEN RAWAT JALAN POLA INTERNA DI RSUD KOTA MAKASSAR
}

\author{
Andi Riska Gunawati', Andi Weri Sompa ${ }^{2}$, Muh. Ikhsan ${ }^{3}$, and Samhi Mua'wan Djamal ${ }^{4}$ \\ 1,2,3,4 Universitas Muhammadiyah Makassar \\ e-mail: andriska.gunawati@yahoo.co.id
}

\begin{abstract}
For knowing the relation of hypertension with cognitive function in outpatients interna poly in RSU D of Makassar City. Methods: This research type is analytic observational study with a cross sectional approach. The subjects in this study amounted to 60 respondents. The study was conducted in RSUD of Makassar City on 12th December 2014 until 27th January 2015. Samples were taken by purposive sampling. Data were obtained through direct interviews by using Mini Mental State Examination (MMSE) and physical examinations of blood pressure measurement. Data analysis was carried out in stages include univariate analysis, bivariate analysis by using Chi-square test on SPSS program. Results : The results of statistical tests by using chi-square indicate that there is relation of hypertension with cognitive function ( $p=0,024 ; O R=9,923$ dan 95\% $C I=0,950$ $103,701)$. Beside it, there is also the relation of long history of hypertension with cognitive function $(p=0,000$; $O R=39,000$ dan 95\% CI =3,262-466,253). Conclusion: There is the relation of hypertension with cognitive function by using Mini Mental State Examination (MMSE). There is also the relation of long history of hypertension with cognitive function.
\end{abstract}

Keywords : Hypertension, cognitive function

\begin{abstract}
Abstrak
Untuk mengetahui hubungan hipertensi dengan fungsi kognitif pada pasien rawat jalan interna poli di RSUD Kota Makassar. Metode: Jenis penelitian ini adalah penelitian observasional analitik dengan pendekatan cross sectional. Subjek dalam penelitian ini berjumlah 60 responden. Penelitian dilakukan di RSUD Kota Makassar pada 12 Desember 2014 hingga 27 Januari 2015. Sampel diambil secara purposive sampling. Data diperoleh melalui wawancara langsung dengan menggunakan Mini Mental State Examination (MMSE) dan pemeriksaan fisik pengukuran tekanan darah. Analisis data dilakukan secara bertahap meliputi analisis univariat, analisis bivariat dengan menggunakan uji Chi-square pada program SPSS. Hasil: Hasil uji statistik dengan menggunakan chi-square menunjukkan bahwa ada hubungan hipertensi dengan fungsi kognitif $(p=0,024 ; \mathrm{OR}=$ 9,923 dan $95 \% \mathrm{CI}=0,950$ - 103,701). Selain itu, ada juga hubungan sejarah panjang hipertensi dengan fungsi kognitif ( $p=0,000 ; O R=39,000$ dan 95\% CI = 3,262 - 466,253). Kesimpulan: Ada hubungan hipertensi dengan fungsi kognitif dengan menggunakan Mini Mental State Examination (MMSE). Ada juga hubungan sejarah panjang hipertensi dengan fungsi kognitif.
\end{abstract}

Kata kunci: Hipertensi, fungsi kognitif

\section{PENDAHULUAN}

Kita hidup dalam lingkungan yang berubah dengan cepat. Di seluruh dunia, kesehatan manusia sedang ditentukan oleh faktor yang sama: penuaan, demografi, urbanisasi yang cepat, dan gaya hidup tidak sehat. Salah satu contoh yang paling mencolok dari pergeseran ini adalah kenyataan bahwa penyakit tidak menular seperti penyakit jantung, kanker, diabetes dan penyakit paru-paru kronis telah mengambil alih sebagai penyebab terkemuka kematian di dunia. Salah satu faktor risiko utama untuk penyakit jantung ialah hipertensi. Hipertensi sudah mempengaruhi satu miliar orang di seluruh dunia, yang menyebabkan serangan jantung dan stroke. ${ }^{1}$ 
Menurut World Health Organization (WHO), hipertensi dikatakan sebagai issue utama dalam kesehatan publik karna dari data yang diperoleh dari jumlah tersebut, komplikasi jumlah hipertensi untuk 9,4 juta kematian di seluruh dunia setiap tahun . Hipertensi bertanggung jawab untuk setidaknya $45 \%$ dari kematian akibat penyakit jantung (total mortalitas penyakit jantung iskemik), dan 51\% dari kematian akibat stroke. Pada regio Asia TimurSelatan diperoleh data statistik menurut usia 25 tahun keatas , $39 \%$ pada pria dan $36 \%$ pada wanita. ${ }^{1}$

Menurut Riset Kesehatan Dasar (Riskesdas) tahun 2013, prevalensi hipertensi pada umur $\geq 18$ tahun di Indonesia yang didapat melalui jawaban pernah didiagnosis tenaga kesehatan sebesar 9,4 \%, sedangkan yang pernah didiagnosis tenaga kesehatan atau sedang minum obat hipertensi sendiri sebesar 9,5 $\%$. Jadi, terdapat $0,1 \%$ penduduk yang minum obat sendiri, meskipun tidak pernah didiagnosis hipertensi oleh tenaga kesehatan (nakes). Prevalensi hipertensi di Indonesia berdasarkan hasil pengukuran pada umur $\geq 18$ tahun sebesar $25,8 \%$. Jadi cakupan nakes hanya $36,8 \%$, sebagian besar $(63,2 \%)$ kasus hipertensi di masyarakat tidak terdiagnosis. Profil Kesehatan Indonesia tahun 2013, prevalensi hipertensi di Sulawesi Selatan sendiri usia $\geq 18$ tahun diperoleh data berdasarkan diagnosis oleh nakes 10,3\%, riwayat sedang minum obat antihipertensi $10,5 \%$ dan dari hasil pengukuran diperoleh $28,1 \%{ }^{3}$

Menurut Profil Kesehatan Kota Makassar tahun 2013 , hipertensi menempati urutan ketiga dengan jumlah kasus 445, setelah asthma 705 kasus, dan jantung 469 kasus. $^{4}$

Hipertension and Vascular Cognitive Impairment yang merupakan bagian dari $5^{\text {th }}$ Scientific Meeting On Hypertension, di Jakarta, 26 Februari 2011, dikatakan bahwa dalam praktik sehari-hari, gangguan kognitif pada penderita hipertensi kurang diperhatikan. Hanya penderita hipertensi yang telah mengalami stroke baru diperhatikan ada tidaknya gangguan kognitif. Pendapat yang demikian ini merupakan kesimpulan yang sangat salah.. Hasil penelitian menunjukkan bahwa hipertensi berhubungan dengan silent brain disorders dan gangguan kognitif. Hipertensi juga dapat menyebabkan dementia tanpa mengalami stroke. Gangguan ini dapat berupa gangguan kognitif ringan (tipe Pre-dementia Alzheimer) atau vascular cognitive impairment no dementia (Pre-vascular dementia). ${ }^{7}$

Elias et al., (2004) juga melakukan penelitian yang sama secara cross sectional. Dilakukan terhadap 529 partisipan dengan membaginya atas dua kelompok. Umur 18 - 46 tahun kelompok umur pertama, dan umur 47 - 83 tahun kelompok umur kedua. Fungsi kognitif di nilai dengan tes the Wechsler Adult Intelligence Scale. Hasil yang didapatkan, dimana tingginya tekanan darah sistolik, tekanan darah diastolik, dan tekanan arteri rata-rata berhubungan secara bermakna dengan penurunan fungsi kognitif terhadap kedua kelompok. Pada kelompok dewasa muda tekanan darah rentan terhadap terjadinya penurunan fungsi kognitif seperti halnya yang terjadi pada usia yang lebih tua. ${ }^{8}$

Hipertensi pada setengah baya dapat menyebabkan disfungsi endotel, terjadi penurunan autoregulasi, inflamasi serta mikrovaskuler dan penyakit kardiovaskular, yang semuanya terkait dengan penyakit yang menyebabkan penurunan kognitif dengan mengganggu pasokan darah otak. Penyakit mikrovaskuler pada otak telah dikaitkan dengan hipoperfusi regional dan kehilangan otak volume. ${ }^{10}$

Sedangkan J. Birn, 2009 dalam penelitiannya mnyimpulkan melalui studi Cross-sectional menunjukkan hubungan campuran antara tekanan darah tinggi dan kognisi, dengan banyak penelitian yang menunjukkan tidak ada korelasi. Penelitian secara acak menunjukkan heterogen dan kadang-kadang bertentangan dengan efek 
dari tekanan darah yang yang menurunkan fungsi kognitif. Alasan heterogenitas ini mencakup dari beberapa mekanisme yang mempengaruhi hipertensi otak, berbagai instrumen kognitif digunakan untuk penilaian dan perbedaan dalam perawatan antihipertensi. ${ }^{11}$

Berdasarkan latar belakang diatas dimana terlihat bahwa masih kontroversialnya hubungan antara hipertensi terhadap fungsi kognitif,dan masih kurangnya penelitian yang menitikberatkan pada fungsi kognitif seseorang yang memiliki riwayat hipertensi, serta belum jelasnya kisaran tekanan darah yang sangat mempengaruhi fungsi kognitif, maka peneliti tertarik untuk melakukan penelitian mengenai hubungan hipertensi dengan fungsi kognitif pada pasien rawat jalan poli interna di RSUD Kota Makassar.

\section{METODE}

Penelitian ini bersifat observasional analitik dengan pendekatan studi potong lintang (cross sectional). Penelitian dilakukan terhadap pasien rawat jalan poli interna usia 25-59 tahun yang memiliki riwayat hipertensi di RSUD Kota Makassar pada bulan Desember 2014 Januari 2015. Populasi dalam penelitian ini adalah seluruh pasien rawat jalan RSUD Kota Makassar. Sampel yang diambil adalah pasien rawat jalan poli interna yang memiliki riwayat hipertensi pada usia 25 59 tahun yang memenuhi kriteria inklusi, sampel minimal adalah sebanyak 53 orang. Pada penelitian ini, teknik penarikan sampel menggunakan tekhnik purposive sampling. Untuk penelitian ini, diperoleh data melalui data primer, yaitu dengan cara melakukan pengukuran tekanan darah \& penilaian langsung menggunakan Mini Mental State Examination (MMSE). Pemilihan sampel terdiri dari kriteria inklusi yaitu Pasien rawat jalan poli interna yang memiliki riwayat hipertensi usia 25 - 59 tahun di RSUD Kota Makassar dan eksklusi yaitu Mempunyai riwayat stroke,
Mempunyai riwayat Traumatic Brain Injury. Mempunyai riwayat DM, Mempunyai riwayat epilepsi, Mempunyai riwyat tumor otak.

Analisis data dilakukan untuk mengetahui hubungan antara hipertensi terhadap gangguan fungsi kognitif melalui uji statistik menggunakan metode chisquare. Data dianalisis dengan Menggunakan program SPSS Statistics v.21 MacOSX Multilingual.

\section{HASIL DAN PEMBAHASAN}

\section{Deskripsi karakteristik responden}

Karakteristik responden mencakup umur pasien, jenis kelamin, pendidikan, pekerjaan, dan unsur MMSE yang terganggu.

\section{Umur Pasien}

Tabel 1. Distribusi Frekuensi HIpertensi Berdasarkan Umur Responden di RSUD Kota Makassar Tahun 2014

\begin{tabular}{ccc}
\hline Umur & Frekuensi & Presentase \\
\hline$<50$ tahun & 13 & 21,7 \\
\hline$\leq 50$ tahun & 47 & 78,3 \\
\hline Total & $\mathbf{6 0}$ & $\mathbf{1 0 0}$
\end{tabular}

Sumber: Data Primer 2015

Berdasarkan tabel 1 dapat dilihat bahwa frekuensi umur responden terbanyak adalah dari kelompok umur $\geq 50$ tahun sebanyak 47 responden (78,3\%). Kemudian diikuti dengan kelompok umur $<50$ tahun sebanyak 13 responden $(21,7 \%)$. Dengan rata-rata umur pasien adalah 54 tahun.

\section{Jenis Kelamin}

Tabel 2. Distribusi Frekuensi HIpertensi Berdasarkan Jenis Kelamin Responden di RSUD Kota Makassar Tahun 2014

\begin{tabular}{ccc}
\hline Jenis Kelamin & Frekuensi & Presentase \\
\hline Laki-laki & 33 & 55 \\
\hline
\end{tabular}




\begin{tabular}{ccc}
\hline Perempuan & 27 & 45 \\
\hline Total & $\mathbf{6 0}$ & $\mathbf{1 0 0}$ \\
\hline
\end{tabular}

Sumber: Data Primer 2015

Berdasarkan tabel 2 dapat dilihat bahwa frekuensi jenis kelamin responden terbanyak adalah laki-laki sebanyak 33 responden (55\%), kemudian diikuti perempuan sebanyak 27 responden (45\%). Dengan rata-rata jenis kelamin pasien adalah laki-laki.

\section{Pendidikan}

Tabel 3. Distribusi Frekuensi HIpertensi Berdasarkan Pendidikan Responden di RSUD Kota Makassar Tahun 2014

\begin{tabular}{ccc}
\hline Pendidikan & Frekuensi & Presentase \\
\hline Non Sarjana & 35 & 58,3 \\
\hline Sarjana & 25 & 41,7 \\
\hline Total & $\mathbf{6 0}$ & $\mathbf{1 0 0}$
\end{tabular}

Sumber: Data Primer 2015

Berdasarkan tabel 3 dapat dilihat bahwa pasien (responden) memiliki berbagai latar belakang tingkat pendidikan yang berbeda - beda. Dimana latar belakang pendidikan pasien yang terbanyak adalah non sarjana yaitu sebanyak 35 responden $(58,3 \%)$, kemudian diikuti dengan pasien yang memiliki latar pendidikan berupa sarjana yaitu sebanyak 25 responden (41,7\%). Dengan rata-rata latar belakang pendidikan yaitu non sarjana.

\section{Pekerjaan}

Tabel 4. Distribusi Frekuensi HIpertensi Berdasarkan Pekerjaan Responden di RSUD Kota Makassar Tahun 2014

\begin{tabular}{ccc}
\hline Pekerjaan & Frekuensi & Presentase \\
\hline IRT & 16 & 26,7 \\
\hline PNS & 15 & 25 \\
\hline Wiraswasta & 25 & 41,7 \\
\hline Pensiunan & 4 & 6,7 \\
\hline Total & $\mathbf{6 0}$ & $\mathbf{1 0 0}$ \\
\hline
\end{tabular}

Sumber: Data Primer 2015
Berdasarkan tabel 4 dapat dilihat bahwa responden memiliki berbagai latar belakang pekerjaan yang berbeda. Dimana jenis pekerjaan responden terbanyak yaitu wiraswasta sebanyak 25 responden (41,7 \%), kemudian diikuti PNS sebanyak 15 responden $(25,0 \%)$, Ibu Rumah Tangga sebanyak 16 responden $(26,7 \%)$, serta pensiunan sebanyak 4 orang $(6,7 \%)$. Dengan rata-rata pekerjaan adalah wiraswasta.

\section{Unsur MMSE Yang Terganggu}

Tabel 5. Distribusi Frekuensi Hipertensi Berdasarkan Unsur MMSE Responden di RSUD Kota Makassar Tahun 2014

\begin{tabular}{ccc}
\hline Unsur MMSE & Frekuensi & Presentase \\
\hline Orientasi & 2 & 3,3 \\
\hline Registrasi & 1 & 1,7 \\
\hline $\begin{array}{c}\text { Atensi dan } \\
\text { Kalkulasi }\end{array}$ & 13 & 21,7 \\
\hline Recall & 40 & 66,7 \\
\hline Bahasa & 4 & 6,7 \\
\hline Total & $\mathbf{6 0}$ & $\mathbf{1 0 0}$
\end{tabular}

Sumber: Data Primer 2015

Berdasarkan tabel 5 dapat dilihat bahwa unsur Mini Mental State Examination (MMSE) yang terganggu terbanyak yaitu recall (mengingat kembali) yang dialami oleh sebanyak 40 responden $(66,7 \%)$, kemudian diikuti Atensi \& Kalkulasi yang dialami oleh 13 responden $(21,7 \%)$, Bahasa dialami oleh sebanyak 4 responden $(6,7 \%)$, Orientasi oleh sebanyak 2 responden $(3,3 \%)$, serta yang terakhir Registrasi sebanyak 1 responden $(1,7 \%)$. Dengan rata-rata unsur Mini Mental State Examination (MMSE) yang sangat terganggu yaitu recall (mengingat kembali).

\section{Analisis Univariat}

Analisis univariat dilakukan untuk melihat gambaran distribusi frekuensi dari masing-masing variabel yang diteliti yaitu 
grade hipertensi, lama riwayat hipertensi, dan interpretasi kognitif.

\section{Grade Hipertensi}

Tabel 6. Distribusi Frekuensi HIpertensi Berdasarkan Grade Hipertensi Responden di RSUD Kota Makassar Tahun 2014

\begin{tabular}{ccc}
\hline $\begin{array}{c}\text { Grade } \\
\text { Hipertensi }\end{array}$ & Frekuensi & Presentase \\
\hline I & 16 & 26,7 \\
\hline II & 44 & 73,7 \\
\hline Total & $\mathbf{6 0}$ & $\mathbf{1 0 0}$ \\
\hline
\end{tabular}

Sumber: Data Primer 2015

Berdasarkan tabel 6 dapat dilihat bahwa sebagian besar pasien menderita hipertensi yang berada pada grade 2 , yang ditunjukkan pada data sebanyak 44 responden $(73,3 \%)$, kemudian diikuti oleh pasien yang menderita hipertensi pada grade 1 sebanyak 16 responden $(26,7 \%)$. Dengan rata-rata tekanan sistolik yaitu $160 \mathrm{mmHg}$, dan tekanan diastolik yaitu $100 \mathrm{mmHg}$.

\section{Lama Riwayat Hipertensi}

Tabel 7. Distribusi Frekuensi HIpertensi Berdasarkan Lama Riwayat Hipertensi Responden di RSUD Kota Makassar Tahun 2014

\begin{tabular}{ccc}
\hline Lama HT & Frekuensi & Presentase \\
\hline$<5$ tahun & 7 & 11,7 \\
\hline$>5$ tahun & 53 & 88,3 \\
\hline Total & $\mathbf{6 0}$ & $\mathbf{1 0 0}$
\end{tabular}

Sumber: Data Primer 2015

Berdasarkan tabel 7 dapat dilihat bahwa tidak sedikit responden yang memiliki riwayat hipertensi hingga bertahun - tahun. Dimana frekuensi lama riwayat hipertensi yang diderita oleh responden terbanyak yaitu $>5$ tahun sebanyak 53 responden $(88.3 \%)$, kemudian diikuti pada range $\leq 5$ tahun sebanyak 7 responden $(11,7 \%)$. Dengan rata-rata lama riwayat hipertensi yaitu 8 tahun.

\section{Interpretasi Kognitif}

Tabel 8. Distribusi Frekuensi HIpertensi Berdasarkan Interpretasi Kognitif Responden di RSUD Kota Makassar Tahun 2014

\begin{tabular}{ccc}
\hline $\begin{array}{c}\text { Interpretasi } \\
\text { Kognitif }\end{array}$ & Frekuensi & Presentase \\
\hline Normal & 4 & 6,7 \\
\hline $\begin{array}{c}\text { Probable } \\
\text { gangguan } \\
\text { Kognitif }\end{array}$ & 56 & 93,3 \\
\hline Total & $\mathbf{6 0}$ & $\mathbf{1 0 0}$ \\
\hline Sumbr
\end{tabular}

Sumber: Data Primer 2015

Berdasarkan table 5.8 dapat disimpulakan bahwa hampir seluruh pasien hipertensi mengalami penurunan fungsi kognitif, sangat terlihat bahwa probable gangguan kognitif dialami oleh sebanyak 56 responden $(93,3 \%)$, sedangkan yang memiliki fungsi kognitif normal hanya 4 orang $(6,7 \%)$. Dengan rata-rata fungsi kognitif yaitu probable gangguan kognitif.

\section{Analisis Bivariat}

Analisis bivariat dilakukan untuk melihat hubungan antara variabel independen (hipertensi) dengan variabel dependen (fungsi kognitif) menggunakan uji Chi-Square.

Tabel 9. Distribusi Frekuensi HIpertensi Berdasarkan Interpretasi Kognitif Responden di RSUD Kota Makassar Tahun 2014

$\begin{array}{lllll}\text { Interpretasi } & \text { Frekuensi } & \text { P } & \text { OR } & \text { 95\%CI }\end{array}$




\begin{tabular}{|c|c|c|c|c|c|c|c|c|c|}
\hline \multirow[t]{3}{*}{ Kognitif } & \multicolumn{6}{|c|}{ Probable } & & & \\
\hline & \multicolumn{2}{|c|}{ Normal } & \multicolumn{2}{|c|}{$\begin{array}{c}\text { Gangguan } \\
\text { Kognitif }\end{array}$} & \multicolumn{2}{|c|}{ Total } & & & \\
\hline & f & $\%$ & f & $\%$ & f & $\%$ & \multirow{3}{*}{0,024} & \multirow{3}{*}{9,923} & \multirow{3}{*}{$\begin{array}{c}0,950- \\
103,701\end{array}$} \\
\hline I & 3 & 18,8 & 13 & 81,3 & 16 & 100 & & & \\
\hline II & 1 & 2,3 & 43 & 97,7 & 44 & 100 & & & \\
\hline Total & 4 & 6,7 & 56 & 93,3 & 60 & 100 & & & \\
\hline
\end{tabular}

Sumber: Data Primer 2015

Dari tabel 9 dapat dilihat distribusi pasien hipertensi grade 1 yang memiliki fungsi kogntif normal sebanyak 3 responden $(18,8 \%)$, dan yang mengalami probable gangguan kognitif sebanyak 13 responden $(81,3 \%)$, Sedangkan pada pasien hipertensi grade 2 yang memiliki fungsi kognitif normal yaitu 1 responden $(2,3 \%)$ dan yang mengalami probable gangguan kognitif sebanyak 43 orang $(97,7 \%)$.

Dari hasil analisis untuk $p$ value 0.024 hipotesis 0 ditolak dan hipotesis alternatif diterima artinya ada hubungan hipertensi dengan fungsi kognitif menggunakan Mini Mental State Examination (MMSE). Nilai OR adalah 9,923 lower 0,950 dan upper 103,701. Responden yang menderita hipertensi grade II 9,923 kali lebih beresiko mengalami penurunan fungsi kognitif dibandingkan responden yang menderita hipertensi grade I dimana convident interval kemungkinan 0,950 kali lipat sampai 103,701 kali lipat.

Tabel 10. Distribusi Frekuensi Hubungan Lama Riwayat Hipertensi dengan Fungsi Kognitif di RSUD Kota Makassar Tahun 2014

\begin{tabular}{|c|c|c|c|c|c|c|c|c|c|}
\hline \multirow{3}{*}{$\begin{array}{c}\text { Interpretasi } \\
\text { Kognitif }\end{array}$} & \multicolumn{6}{|c|}{ Frekuensi } & \multirow[b]{2}{*}{$\mathbf{P}$} & \multirow[b]{2}{*}{ OR } & \multirow[b]{2}{*}{$95 \% \mathrm{CI}$} \\
\hline & \multicolumn{2}{|c|}{ Normal } & \multicolumn{2}{|c|}{$\begin{array}{c}\text { Probable } \\
\text { Gangguan } \\
\text { Kognitif }\end{array}$} & \multicolumn{2}{|c|}{ Total } & & & \\
\hline & f & $\%$ & f & $\%$ & f & $\%$ & \multirow{3}{*}{0,000} & \multirow{3}{*}{39,000} & \multirow{3}{*}{$\begin{array}{c}3,262- \\
466,253\end{array}$} \\
\hline$<5$ Tahun & 3 & 42,9 & 4 & 57,1 & 7 & 100 & & & \\
\hline$>5$ tahun & 1 & 2,9 & 52 & 98,1 & 53 & 100 & & & \\
\hline Total & 4 & 6,7 & 56 & 93,3 & 60 & 100 & & & \\
\hline
\end{tabular}

Sumber: Data Primer 2015

Dari tabel 10 dapat dilihat distribusi responden dengan riwayat lama hipertensi $\leq 5$ tahun yang memiliki fungsi kognitif normal sebanyak 3 responden (42,9\%),sedangkan yang mengalami probable gangguan kognitif sebanyak 4 responden $(57,1 \%)$. Pada responden dengan riwayat lama hipertensi $>5$ tahun yang memiliki fungsi kognitif normal yaitu 1 orang $(1,9 \%)$, sedangkan yang mengalami probable gangguan kognitif sebanyak 52 responden $(98,1 \%)$.

Dari hasil analisis untuk $p$ value 0.000 , hal ini makin mendukung bahwa artinya riwayat lama hipertensi juga berhubungan dengan fungsi kognitif. Semakin lama seseorang mempunyai riwayat hipertensi, maka makin mempengaruhi pula fungsi kognitif orang tersebut. Nilai OR adalah 39,000 lower 3,262 dan upper 466,253. Responden yang memiliki lama riwayat hipertensi $>5$ tahun 39,000 kali lebih beresiko mengalami penurunan fungsi kognitif dibandingkan responden yang memiliki lama riwayat hipertensi $\leq 5$ tahun dimana convident interval kemungkinan 3,262 kali lipat sampai 466,253 kali lipat.

\section{Hubungan Hipertensi Dengan Fungsi Kognitif}


Dari hasil pengumpulan data yang telah dilakukan pada pasien hipertensi di RSUD Kota Makassar dan telah dilakukan pengolahan data, maka bab ini merupakan pembahasan tentang hasil penelitian yang telah didapatkan.

Dari hasil penelitian yang telah dilakukan dapat dilihat hubungan hipertensi dengan fungsi kognitif sangat bermakna, dimana hipertensi mempengaruhi fungsi kognitif pada mereka yang memiliki riwayat tersebut. Dimana pada pasien hipertensi grade 1 hanya sebagian kecil yang mengalami fungsi kognitif normal. Dan pada pasien hipertensi grade 2 hampir seluruhnya mengalami probable gangguan kognitif.. Hal ini dibuktikan dengan hasil Uji ChiSquare, dimana didapatkan nilai $p=0,024$ $(<0,05)$ artinya ada hubungan hipertensi dengan fungsi kognitif.

Elias (2004) juga melakukan penelitian yang sama secara cross sectional di Australia. Dilakukan terhadap 529 partisipan dengan membaginya atas dua kelompok. Umur $18-46$ tahun kelompok umur pertama, dan umur 47 - 83 tahun kelompok umur kedua. Fungsi kognitif di nilai dengan tes the Wechsler Adult Intelligence Scale. Hasil yang didapatkan, dimana tingginya tekanan darah sistolik, tekanan darah diastolik, dan tekanan arteri rata-rata berhubungan secara bermakna dengan penurunan fungsi kognitif terhadap kedua kelompok. Pada kelompok dewasa muda tekanan darah rentan terhadap terjadinya penurunan fungsi kognitif seperti halnya yang terjadi pada usia yang lebih tua. ${ }^{33}$

Dalam penelitian ini juga menyimpulkan bahwa pada grade 1 Hipertensi akan mengakibatkan penurunan kognitif yang relatif masih kecil sekitar 8 , $12 \%$ dimana pernyataan tersebut telah dibuktikan dengan hasil penelitian yang telah dilakukan oleh penelti yang memperlihatkan pada pasien hipertensi grade 1 jumlah pasien yang mengalami probable gangguan kognitif masih relatif dalam jumlah kecil, hal ini sangat berbeda secara signifikan pada pasien hipertensi grade 2, artinya semakin tinggi grade hipertensi seseorang, akan semakin tinggi pula resiko pasien tersebut mengalami penurunan fungsi kognitif. ${ }^{33}$

Dari hasil analisis data yang dilakukan, terlihat bahwa hipertensi mempunyai hubungan bermakna dengan fungsi kognitif yang sangat menitikberatkan pada kategori probable gangguan kognitif dan tidak ada yang sampai mengalami defenite gangguan kognitif. Reitz (2007) dalam penelitiannya di Northem Manhattam (Washington Heights, Hamilton Heights, Inwood) menggunakan studi kohort longitudinal dengan metode pengambilan sampel secara random sampling pada usia $\leq 60$ tahun, juga menunjukkan hubungan hipertensi dengan fungsi kognitif khususnya sebatas probable gangguan kognitif (Mild Cognitive Impairment) ${ }^{34}$

Hipertensi di usia pertengahan dikaitkan dengan mild cognitive impairment. Tingginya tekanan sistolik di usia pertengahan akan meningkatkan risiko aterosklerosis, meningkatkan jumlah lesi iskemik substansia alba, juga meningkatkan jumlah plak neuritik dan tangles di neokorteks dan hipokampus serta meningktkan atrofi hipokampus dan amigdala. Masing-masing kelainan tersebut dapat berpengaruh negatif terhadap fungsi kognitif. ${ }^{35}$

Perubahan fungsi kognitif telah dilaporkan berasal dari pasien yang mempunyai riwayat hipertensi.selain itu juga ditemukan bahwa pasien dengan hipertensi dengan konfluen age related white mater change (ARWMC) memperoleh hasil yang lebih buruk pada tes fungsi kognitif menggunakan MMSE. ${ }^{36}$

Dari hasil penelitian ini juga dapat dilihat bahwa kelompok usia $<50$ tahun mengalami hipertensi sebanyak 13 responden, sedangkan kelompok usia $\geq 50$ tahun mengalami hipertensi sebanyak 47 orang. Sehingga dapat disimpulkan bahwa peningkatan tekanan darah yang dialami seseorang dapat dipengaruhi oleh faktor usia. Menurut sebuah penelitian oleh 
Zuraidah (2012) di Kec. Kemuning Kota Palembang, terdapat hubungan antara usia dengan kejadian hipertensi dari 113 responden yang kelompok umur $\geq 35$ tahun mengalami hipertensi sebanyak 75 responden $(66,4 \%)$, sedangkan yang berumur $<35$ tahun mengalami hipertensi sebanyak 7 responden $(14,9 \%) .{ }^{37}$ Sugiharto (2007) dalam penelitiannya mengenai faktor resiko mengalami hipertensi grade II di Semarang, terbukti bahwa umur 46-55 tahun merupakan faktor resiko dengan nilai $p=0,0001 .^{38}$

Selain faktor usia, jenis kelamin juga merupakan faktor resiko hipertensi. Dari hasil analisis data yang diperoleh, pria menderita hipertensi sebanyak 33 respoden, dan perempuan sebanyak 27 responden. Menurut Departemen Kesehatan RI (2006), pria lebih banyak yang menderita hipertensi dibandingkan dengan wanita, dengan rasio sekitar 2,29 untuk peningkatan tekanan darah sistolik. ${ }^{29}$ Pria diduga memiliki gaya hidup yang cenderung dapat meningkatkan tekanan darah dibanding wanita, salah satunya menurut penelitian Sugiarto (2007) yaitu kebiasaan merokok pada pria terbukti merupakan faktor resiko hipertensi dengan nilai $p=0,0001 .^{38}$ Namun setelah memasuki menopause, prevalensi hipertensi pada wanita meningkat. Wanita dipengaruhi oleh beberapa hormon termasuk hormon estrogen yang melindungi wanita dari hipertensi dan komplikasinya termasuk penebalan dinding pembuluh darah atau aterosklerosis. Wanita usia produktif sekitar $\quad 30-40$ tahun. ${ }^{19}$ Kebiasaan mengkonsumsi asin, lemak jenuh, jelantah, stres, ataupun penggunaan pil KB lebih dari 12 tahun juga merupakan faktor resiko hipertensi. ${ }^{38}$

\section{Hubungan Lama Riwayat Hipertensi Dengan Fungsi Kognitif}

Penurunan fungsi kognitif juga dapat didukung oleh lama riwayat hipertensi, dimana selain grade hipertensi yang semakin tinggi, ternyata riwayat hipertensi yang semakin lama, maka akan semakin mempengaruhi fungsi kognitif seseorang. Dari hasil analisis bivariat yang telah dilakukan dapat dilihat hubungan lama riwayat hipertensi dengan fungsi kognitif sangat bermakna, dimana selain grade hipertensi yang semakin tinggi, ternyata riwayat hipertensi yang semakin lama, maka akan semakin mempengaruhi fungsi kognitif seseorang. Pada pasien yang memiliki riwayat hipertensi $<5$ tahun masih terdapat pasien yang memiliki fungsi kognitif normal dan sebagian kecil yang mengalami probable gangguan kognitif, sedangkan pada pasien yang memiliki riwayat hipertensi $\geq 5$ tahun makin meningkat pula jumlah pasien yang mengalami probable gangguan kognitf. Hal ini dibuktikan dengan hasil Uji ChiSquare, dimana didapatkan nilai $\mathrm{p}=0,000$ $(<0,05)$ artinya ada hubungan lama riwayat hipertensi dengan fungsi kognitif.

Knehct (2008) juga dalam penelitiannya dengan metode cross sectional menunjukkan hubungan bermakna hipertensi dengan fungsi kognitif pada usia $<60$ tahun $(\mathrm{p}<0.005)$, dan akan mengalami peningkatan terhadap resiko penurunan fungsi kognitif bagi mereka yang telah memiliki riwayat hipertensi selama \pm 6 tahun. ${ }^{39}$

Hal ini sesuai dengan teori bahwa hipertensi dalam jangka waktu lama atau kronik menginduksi remodelling arteri cerebral menyebabkan penurunan lumen tersebut. Hipertensi juga menyebabkan kerusakan terhadap sawar darah otak, memajankan neuron-neuron terhadap molekul cytotoxic sehingga menyebabkan hilangnya neuron-neuron. Gangguan pada autoregulasi cerebral pada pasien dengan riwayat hipertensi dihubungakn dengan White Matter Lessions. Lesi tersebut dihubungkan terhadap tekanan darah yang lebih tinggi. Matti (2014), dalam sebuah studi populasi prospektif, dimana jangka panjang efek hipertensi diperiksa. Hasilnya ditemukan bahwa adanya lesi pada pia mater juga dihubungkan dengan 
peningkatan tekanan diastolik $(>10$ $\mathrm{mmHg}$ ), tekanan sistolik ( $>40 \mathrm{mmHg})$, tekanan pulsasi $(>24 \mathrm{mmHg})$ dan tekanan arteri rerata $(>6 \mathrm{mmHg})$ selama 12 tahun follow up. Hiperintensitas pia mater berhubungan dengan disfungsi kognitif dan dengan progresifitas pada defisit kognitif. ${ }^{10,40,41}$

Hasil penelitian tersebut sesuai dengan penelitian yang dilakukan oleh Christian (2014), dibandingkan dengan normotensives, hipertensi menyajikan penurunan progresif dalam aliran darah otak terutama untuk hippocampus, cingulate anterior gyrus dan korteks prefrontal, daerah dianggap terlibat dalam memori, fungsi eksekutif dan perhatian. ${ }^{6}$

Thomas (2011), dari hasil studinya yang mendukung penyebab hipoperfusi cerebral dalam patogenesis hipertensi berkaitan dengan penurunan fungsi kognitif. Sehingga menegaskan hubungan antara kinerja pada Mini Mental State Examination (MMSE) dan hipoperfusi di frontal, parietal, dan korteks temporal. Dalam studi yang dilakukannya, perhatian dan perhitungan menunjukkan korelasi dengan penurunan aliran darah otak di korteks frontal, sedangkan orientasi dan recall terkait dengan aliran darah otak di daerah posterior. ${ }^{9}$

Hal senada juga dikatakan christian (2014) bahwa hubungan antara hipertensi dan penurunan kognitif, menurut yang diterima paling banyak hipotesis, dimediasi oleh kerusakan pembuluh darah otak seperti lesi white matter, yang terdeteksi sebagai hyperintensities. Memang, gangguan pada white matter yang menghubungkan lobus frontal dengan struktur kortikal dan subkortikal lainnya dapat mempengaruhi perhatian / fungsi eksekutif dan kecepatan pemrosesan. ${ }^{6}$

Dari hasil analisis data yang dilakukan masih terdapat responden yang memiliki fungsi kognitif normal, karena hal tersebut dapat didukung oleh usia yang masih tergolong muda, pendidikan, ataupun pola hidup pasien. Menurut Fernando (2013), bukti baru menunjukkan bahwa olahraga memberikan efek pada kognisi dengan mempengaruhi peristiwa molekuler yang terkait dengan pengelolaan metabolisme energi dan plastisitas sinaptik. ${ }^{42}$ Selain itu menurut Guslinda (2013), menunjukkan hubungan pengaruh senam otak (Brain gym) dengan fungsi kognitif bahkan pada lansia. Sehingga hal tersebut dapat menjaga fungsi kognitif. ${ }^{43}$

\section{KESIMPULAN}

Dari analisis data yang dilakukan, disimpulkan beberapa hal sebagai berikut:

1. Terdapat hubungan antara hipertensi dengan fungsi kognitif.

2. Semakin tinggi grade hipertensi seseorang maka makin menurun fungsi kognitif seseorang.

3. Makin lama riwayat hipertensi makin menurun fungsi kognitif seseorang

\section{DAFTAR PUSTAKA}

1. World Health Organization. A Global Brief On Hypertension : Silent Killer Global Public Health Crisis. 2013. Diakses melalui http://www.who.int pada tanggal 04 oktober 2014

2. Badan Penelitian Dan Pengembangan Kesehatan Kementerian Kesehatan RI. Riset Kesehatan Dasar, 2013. Diakses melalui

http://www.litbang.depkes.go.id pada tanggal 04 Oktober 2014

3. Kementrian Kesehatan RI (2013) Profil Kesehatan Indonesia Tahun 2013. Diakses melalui http://www.depkes.go.id pada tanggal 18 Oktober 2014

4. Dinas Kesehatan. Profil Kesehatan Kota Makassar 2013, 2014. Diakses melalui https://www.google.co.id pada tanggal 04 Oktober 2014.

5. Muliyati H, Syam A, Sirajuddin S. Hubungan Pola Konsumsi Natrium Dan Kalium Serta Aktifitas Fisik Dengan Kejadian Hipertensi Pada Pasien Rawat Jalan Di RSUP Dr. Wahidin Sudirohusodo Makassar. 
Media Gizi Masyarakat Indonesia. Agustus 2011; 1(1) : 46. Diakses melalui http://journal.unhas.ac.id pada tanggal 05 oktober 2014

6. Spinelli C, Caro MF, Schirosi G, et al. Impaired Cognitive Executive Dysfunction In Adult Treated Hypertensives With A Confirmed Diagnosis Of Poorly Controlled Blood Pressure. J Int Med Sci. 2014 May 29; 11(8):771- 2 Diakses melalui http://www.medsci.org pada tanggal 05 Oktober 2014

7. $5^{\text {th }}$ Scientific Meeting On Hypertension . Hipertension And Vascular Cognitive Impairment. Jakarta, 26 Februari 2011. Diakses melalui http://www.jurnalmedika.com pada tanggal 31 Oktober 2014.

8. Zuhir E. Hubungan Gangguan Fungsi Kognitif Dengan Hipertensi Ditinjau Dari Aspek Il-6 Dan TNF-Alfa. Universitas Andalas. 2011: 5-6. Diakses melalui http://pasca.unand.ac.id pada tanggal 20 Oktober 2014

9. Obisesan TO. Hypertension and Cognitive Function. Clin Geriatr Med. 2009 May ; 25(2): 3. Diakses melalui www.ncbi.nlm.nih.gov pada tanggal 11 Oktober 2014

10. Matti H. Theses : The Effect Of Cardiovascular Stress On Cognition And Mortality : Studies On B-Type Natriuretic Peptide Amongst The Elderly Population, Helsinki. Department Of Neurological Sciences, Department Of Clinical Neurophysiology Helsinki University. 2014 : 15. Diakses melalui https://helda.helsinki.fi pada tanggal 04 Oktober 2014

11. Birns J, Kalra L. Cognitive Function And Hypertension. J Hum Hypertens. 24 July 2008; 23: 86. Diakses melalui www.ncbi.nlm.nih.gov/pubmed pada tanggal 04 Oktober 2014

12. RSUD Kota Makassar. Profil Umun RSUD Kota Makassar Tahun 2014
13. Syarif A, Estuningtyas A, Setiawati A. Farmakologi Dan Terapi. 5th rev.ed. Gunawan SG, editor. Jakarta : FKUI, 2012. $342 \mathrm{p}$

14. National Institutes of Health National Heart, Lung, and Blood Institute (2004) Seventh Report Of The Joint National Comitee On Prevention, Detection, Evaluation, Treatment High Blood Pressure, Agustus 2004, diakses 4 oktober 2014 (http://www.nhlbi.nih.gov)

15. Agoes H. Penyakit Usia Tua. 1st ed. Dany F, editor. Jakarta : EGC, 2010. $13-4 p$

16. Reksodiputro A, Madjid A, Rachman AM, et al. Buku Ajar Ilmu Penyakit Dalam. 5th rev. ed. Sudoyo AW. Jakarta : Interna Publishing, 2009. $1081 \mathrm{p}$

17. Harrison. Prinsip - Prinsip Ilmu Penyakit Dalam. 13th rev.ed. Isselbacher KJ, editor. Jakarta : EGC, 2013. $1261-2 \mathrm{p}$

18. Sherwood L. Fisiologi Manusia Dari Sel Ke Sistem .6th rev.ed. Yesdelita N, editor. Jakarta : EGC, 2011. 404- 5, 570-1 p

19. Kartikasari AN. Karya Tulis Ilmiah : Faktor Risiko Hipertensi Pada Masyarakat Di Desa Kabongan Kidul, Kabupaten Rembang. 2012 . Fakultas Kedokteran Universitas Diponegoro.32-8, 41. Diakses melalui http://eprints.undip.ac.id pada tanggal 28 Februari 2015

20. Fuller G. Panduan Praktis Pemeriksaan Neurologis. 1st Engl .ed. Prawira J, editor. Jakarta : EGC, 2008. 31- $6 \mathrm{p}$

21. Mcphee SJ, Ganong WF. Patofisiologi Penyakit. 5th rev.ed. Dany F, editor. Jakarta : EGC, 2010. 182- $4 \mathrm{p}$

22. Sidarta P. 2008. Tata pemeriksaan klinis dalam neurologi. 1st Engl. ed. Jakarta : Dian Rakyat, 2008. 538 p

23. Sacco RL, Kasner SE, Broderick JP, et al. An Updated Definition Of Stroke 
For The 21st Century: Professionals From The American Heart Association. J Am Heart Assoc. 2013 May 17;(44): 2065. Diakses melalui http://www.ncbi.nlm.nih.gov/pubmed pada tanggal 18 Oktober 2014

24. Vijayakumar TM, Sirisha GB, Begam F, et al. Mechanism Linking Cognitive Impairment And Diabetes Mellitus. Eur J Appl Sci. 2012; 4 (1): 01. Diakses melalui http://www.idosi.org pada tanggal 28 Oktober 2014

25. Menon DK, Schwab K, Wright DW, et al. Position Statement: Definition Of Traumatic Brain Injury. Arch Phys Med Rehabil. 2014 Nov; 91:1637. Diakses melalui http://www.ncbi.nlm.nih.gov/pubmed pada tanggal 28 Oktober 2014

26. Menteri Kesehatan Republik Indonesia. Pedoman Rehabilitasi Kognitif. 263/Menkes/SK/II/2010 : 8

27. Sutikno E. Tesis : Hubungan Fungsi Keluarga Dengan Kualitas Hidup Lansia. Program Studi Kedokteran Keluarga. Universitas Sebelas Maret. 2011 : 31. Diakses melalui http://eprints.uns.ac.id pada tanggal 05 Oktober 2014

28. Sadock BJ, Sadock VA. Kaplan \& Sadock Buku Ajar Psikiatri Klinis. 2nd rev. ed. Muttaqin $\mathrm{H}$, editor. Jakarta : EGC, 2010. 53 p

29. Departemen Kesehatan RI. Pedoman teknis tatalaksana penyakit hipertensi. 2006. Direktorat Pengendalian Penyakit Tidak Menular . 25-8. Diakses melalui http://www.depkes.go.id/resources pada tanggal 03 Februari 2015

30. Heword C. Treating Mild Cognitive Impairment. Department of Neurology and Neurosurgery, Mcgill University. 2009: 15. Diakses melalui http://www.alzheimersanddementia.co m pada tanggal 03 Februari 2015

31. Mayo Clinic Staf. Disease and Condition : Mild Cognitive Impairment . 2012. Diakses melalui http://www.mayoclinic.org pada tanggal 05 Maret 2015

32. RSUD Kota Makassar. Daftar 10 Penyakit Terbesar Tahun 2014.

33. Elias PK, Elias MF, Robbins MA, et al. Blood Pressure Related Cognitive Decline : Does Age Make A Difference?. J Am Heart Assoc. 2004 Oct 4; 44: 631. Diakses melalui http://umaine.edu pada tanggal 04 Maret 2015

34. Reitz C, Tang MX, Manly J. Hypertension And The Risk Of Mild Cognitive Impairment. Am Med Assoc. 2007 Dec; 64 (12) : 1737-8. Diakses melalui http://www.ncbi.nlm.nih.gov/pmc pada tanggal 05 Maret 2015

35. Wreksoatmodjo BR. Beberapa kondisi fisik dan Penyakit yang merupakan faktor risiko gangguan fungsi kognitif. Bagian Neurologi FK Universitas Atmajaya. 2014; 41 (1) : 27. Diakses melalui http://www.kalbemed.com pada tanggal 28 Februari 2015

36. Verdelho A, MadureiraS, Ferro JM. Differential Impact Of Cerebral White Matter Changes, Diabetes, Hypertension And Stroke On Cognitive Performance Among NonDisabled Elderly. J Neurol Neurosurg Psychiatry.2007 Apr 30. 78 : 1329. Diakses melalui http://www.ncbi.nlm.nih.gov/pubmed pada tanggal 04 Maret 2015

37. Zuraidah. Analisis Faktor Risiko Penyakit Hipertensi Pada Masyarakat Di Kecamatan Kemuning Kota Palembang Tahun 2012. Poltekes Kesehatan Palembang. 2012. 46. Diakses melalui http://poltekkespalembang.ac.id pada tanggal 26 Februari 2015

38. Sugiharto A. Faktor - Faktor Risiko Hipertensi Grade II Pada Masyarakat. Prodi Magister Epidemiologi Universitas Diponegoro. 2007; 116- 8. Diakses 
melalui http://eprints.undip.ac.id pada tanggal 26 Februari 2015

39. Knecht S, Wersching H, Lohmann H, et al. High Normal Blood Pressure Is Associated With Poor Cognitive Performance. J Am Heart Assoc. 2008 Feb 4; 51 : 663. Diakses melalui http:/hyper.ahajournals.org pada tanggal 05 Maret 2015

40. Pires PW, Ramos CM, Matin N, et al. The Effect Of Hypertension On The Cerebral Circulation. Am J Physiol Heart Circ Physiol. 2013 March 11; $304 . \quad$ Diakses melalui http://www.ncbi.nlm.nih.gov/pmc pada tanggal 05 Februari 2015

41. Iadecola C, Davisson RL. Hypertension And Cerebrovascular Dysfunction. NIH Public Access. 2008 June; 7(6): 4. Diakses melalui http://www.ncbi.nlm.nih.gov/pubmed pada tanggal 05 Maret 2015

42. Fernando GP. The Influence Of Exercise On Cognitive Abilities. Compr Physiol. January 2013. 403. Diakses melalui http://www.ncbi.nlm.nih.gov/pubmed pada tanggal 27 Februari 2015

43. Guslinda, Yolanda Y. Pengaruh Senam Otak Terhadap Fungsi Kognitif Pada Lansia Dengan Dimensia Di Panti Sosial Tresna Werdha Sabai Nan Aluih Sicincin Padang Pariaman Tahun 2013. Stikes Mercubaktijaya Padang. 2013:1. Diakses melalui http://journal.mercubaktijaya.ac.id pada tanggal 28 Februari 2015

44. Hendrik. Sehat dengan shalat. 1st ed. Pendi, editor. Solo : Tiga Serangkai, 2008. 5-8, 17-20 p

45. Sayyid AB. Kedokteran islam : Rasulullah sang dokter. 2nd ed. AlQois, editor. Solo : Tiga serangkai, 2006. 103-4 p

46. Kartanegara M. Nalar Religius : Memahami Hakikat Tuhan, Alam, Dan Manusia. 1st ed. Alkaf $\mathrm{H}$, editor. Jakarta : Erlangga, 2008. 49 p
47. Abidin DZ. Quran Saintifik. 4th ed. Nor Wasir MI, editor. Kuala Lumpur : PTS Millenia SDN. BHD, 2007. 167 p

48. Tim Tafsir Ilmiah Salman ITB. Tafsir salman : Tafsir Ilmiah Juz 'Amma. Bandung : Mizan Pustaka, 2014. 362 $\mathrm{p}$ 